\title{
A BRINQUEDOTECA HOSPITALAR COMO FATOR DE PROMOÇÃO NO DESENVOLVIMENTO INFANTIL: RELATO DE EXPERIÊNCIA
}

\author{
THE HOSPITAL PLAYROOM AS A FACTOR IN THE \\ PROMOTION OF CHILD DEVELOPMENT: REPORT OF \\ EXPERIENCE
}

\author{
Lecila Duarte Barbosa Oliveira ${ }^{1}$ \\ Letícia Macedo Gabarra ${ }^{2}$ \\ Claudete Marcon ${ }^{3}$ \\ Julia Laitano Coelho Silva ${ }^{4}$ \\ Juliana Macchiaverni ${ }^{5}$
}

Oliveira LDB. A brinquedoteca hospitalar como fator de promoção no desenvolvimento infantil: relato de experiência. Rev Bras Crescimento Desenvolv Hum. 2009; 19(2):306-312.

\section{Resumo:}

A internação hospitalar, freqüentemente, é vista pela criança como uma experiência desagradável a qual é acompanhada de dor, ansiedade, medo, além de sensações de abandono e culpa. A brincadeira é a maneira mais autêntica pela qual a criança expressa e elabora suas vivências. O presente artigo tem, então, como objetivo apresentar as atividades desenvolvidas no Projeto: Brinquedoteca Hospitalar: Projeto de Recreação em Enfermaria Pediátrica, realizado no Hospital Universitário da Universidade Federal de Santa Catarina, junto às crianças internadas e acompanhantes. Ele constitui-se num projeto de extensão e pretende ressaltar o papel da brincadeira como promotora de bem estar físico, emocional e amenizadora dos desequilíbrios advindos da doença e do processo de hospitalização, assim como possibilitar a continuidade do desenvolvimento da criança. As atividades realizadas diariamente abrangeram uma gama de situações lúdicas tais como jogos, desenhos, fantoches, entre outros. Observou-se que a intervenção das brinquedistas ajudou a criança a atender as solicitações feitas pelos médicos, entender o processo da doença e, ainda, possibilitou uma melhor interação com a equipe médica. Concluiu-se assim, que a brincadeira, de fato, ameniza os traumas da internação, portanto, não deve ser considerada como uma atividade de tempo livre, mas sim como parte do tratamento, otimizando a intervenção e diminuindo o tempo de internação.

Palavras-chave: hospitalização infantil; brinquedoteca hospitalar; desenvolvimento infantil.

1 Prof. Dra. do Departamento de Psicologia da UFSC, Coordenadora do Projeto Brinquedoteca Hospitalar, lecila@cfh.ufsc.br. Endereço: Rua Capitão Romualdo de Barros n. 965, ap. 402 bloco B, Carvoeira, Florianópolis-SC. CEP: 88040-600

2 Psicóloga do Hospital Universitário da UFSC; Doutoranda do Programa de Pós Graduação em Psicologia da UFSC, leticiagabarra@gmail.com.

3 Psicóloga da Divisão de Pediatria do Hospital Universitário da UFSC, Mestre pelo Programa de Pós Graduação em Psicologia da UFSC, marcon_claudete@hotmail.com.

4 Julia Laitano Coelho Silva - Estagiária do Projeto de extensão da Brinquedoteca Hospitalar, graduanda do Curso de Psicologia da UFSC, julia_laitano@hotmail.com.

5 Juliana Macchiaverni - Estagiária do Projeto de extensão da Brinquedoteca Hospitalar, graduanda do Curso de Psicologia da UFSC, juliana_macc@hotmail.com.

Financimento: Pro-extensão UFSC, 2006. 


\begin{abstract}
:
The hospital is often seen by the child as an unpleasant experience which is accompanied by pain, anxiety, fear and feelings of abandonment and guilt. The play behavior is the way most authentic of the child to express and show their emotions. This article is then to present the activities in the Project: toy library - Draft Recreation in Ward Pediatric, held at the University Hospital of Universidade Federal de Santa Catarina, with hospitalized children and companions. It consists of an extension project and emphasizes the importance of playing activities to promote physical well-being, minimizing the emotional imbalances caused by illness and hospitalization process, it also aims to promote the continued development of the child. The activities included a series of actions, such as games, drawings, puppets, among others. It was observed that the intervention aided children to meet the requests made by physicians, understand the disease process and also aided toward a better interaction with the health staff. Therefore, we conclude that the play actually minimizes the trauma of hospitalization, therefore, should not be taken as a leisure activity but as part of treatment, optimizing the intervention and waning lenght of hospitalization.
\end{abstract}

Key words: infantile hospitalization; toy library; infantile development.

\section{INTRODUÇÃO}

A infância é uma etapa fundamental no desenvolvimento humano, marcada pelas atividades físicas intensas, sendo que estas são necessárias para que a criança possa ir aos poucos explorando e conhecendo o ambiente a sua volta e assim, conseqüentemente, crescendo normalmente e aprimorando seu conhecimento sobre o mundo. Para que ela possa percorrer esta etapa de sua vida sem prejuízos é necessário gozar de saúde. Porém, no decorrer de seu desenvolvimento, as crianças passam também por períodos de doenças, o que muitas vezes pode ser acompanhado de hospitalização. $\mathrm{O}$ adoecimento e a hospitalização na infância são eventos não esperados para esta fase do ciclo vital, assim, são considerados como momentos de crise para a família.

O processo de hospitalização infantil é, sem dúvida, marcante na vida de qualquer criança, uma vez que neste momento ela se percebe frágil e impossibilitada de realizar suas atividades normalmente, alterando a sua rotina diária, como brincar e ir à escola. A imagem de infância é intimamente ligada ao bem estar, energia e alegria, o que torna mais difícil assimilar a doença e a hospitalização nesta fase do ciclo vital, tanto por parte da própria criança como de toda sua rede de apoio.

O ambiente hospitalar é, geralmente, desconhecido para a criança, tanto em seu aspecto físico quanto em sua rotina. Ele possui normas e regras específicas, e a criança e sua família precisam se adaptar a estas condições, como o horário e cardápio para as refeições; uma cama na qual não está acostumada a dormir; roupas diferentes das quais utiliza em casa; banheiro comunitário e falta de privacidade, tanto em relação à proximidade dos leitos quanto a procedimentos médicos invasivos e dolorosos. Estas condições hospitalares podem gerar uma despersonalização do paciente e dificultar no enfrentamento da doença. ${ }^{1,4,11}$

Todas essas mudanças causam um impacto na criança e podem alterar seu comportamento durante e depois da internação. Assim, a hospitalização e o adoecimento podem ser fatores de risco para o desenvolvimento infantil. ${ }^{3,4,5}$ Vale salientar, que as conseqüências da hospitalização, em maior ou menor proporção, depende de diversos fatores, tais como: idade, personalidade da criança, tipo de rela- 
ção pais-filho, reação dos pais para com a doença, tempo de hospitalização, reincidência de internação, as informações que a criança possui sobre seu estado, diagnóstico médico, representações sociais da doença, estratégias de enfrentamento da situação utilizadas pela criança e pela família. 3,5,7

Nesta perspectiva, o enfoque dos estudos iniciais neste contexto (processo de adoecimento - crianças - hospital) tenderam a enfatizar os aspectos negativos da situação de hospitalização e os efeitos potencialmente maléficos desta sobre o comportamento, a vida e o desenvolvimento das crianças e famílias ${ }^{1,4}$. Numa perspectiva mais atual, tem-se enfatizado a dimensão educativa e potencializadora do desenvolvimento humano nas situações de crise, apontando possibilidades de aprendizados significativos relacionados à situação de adoecimento ${ }^{1,3,5,6}$.

Na situação da internação, o hospital passa a ser o microssistema de interação da criança, isto é, parte das suas relações imediatas e com significados específicos para a pessoa. O hospital pode ser considerado como um contexto de desenvolvimento infantil, visto que este local torna-se parte da vivência da criança, interferindo nas suas relações psicossociais. 1,2,9,12,13 Assim a brincadeira pode ser uma forma de enfrentamento desta situação de hospitalização, bem como uma forma de humanizar as relações no contexto de internação.

Portanto, se na educação o brincar serve como recurso metodológico, na saúde também o é. "Já foi comprovado que o brincar, no hospital, humaniza o atendimento, estimula o contínuo e adequado desenvolvimento neuropsicomotor da criança e faz prevenção em saúde mental” (p. 138). ${ }^{15}$ Para que o brincar seja efetivamente exercitado e cumpra seus objetivos no ambiente hospitalar, é fundamental que toda a equipe entenda o significado do brincar para a criança. ${ }^{3,10}$

A importância do brincar no hospital, felizmente, vem sendo valorizada, como se pode verificar na Lei ${ }^{\circ} 11.104$, de 21 de março de 2005, a qual apresenta a obrigatoriedade de instalação de brinquedotecas nas unidades de saúde que ofereçam atendimento pediátrico em regime de internação. De acordo com o Art. $2^{\circ}$ considera-se brinquedoteca, para os efeitos desta Lei, o espaço provido de brinquedos e jogos educativos, destinados a estimular as crianças e seus acompanhantes a brincar. ${ }^{8}$

A existência de brinquedotecas hospitalares ainda está em fase de expansão, os hospitais aos poucos se adequam às necessidades impostas pela legislação vigente, para que o espaço específico destinado para o brincar nas instituições hospitalares torne efetiva a possibilidade lúdica em sua dimensão terapêutica. Essa estratégia pode minimizar o ambiente hostil e estranho da instituição hospitalar, e proporcionar um atendimento global durante a internação, tornando o hospital um contexto de desenvolvimento saudável para as crianças e suas famílias. Assim, o objetivo deste artigo é apresentar as atividades desenvolvidas no Projeto de Extensão: Brinquedoteca Hospitalar Projeto de Recreação em Enfermaria Pediátrica e descrever o papel da brincadeira como promotora de bem estar físico e emocional da criança no ambiente hospitalar.

\section{MÉTODO}

Participantes, Local e Período de realização das atividades

As atividades lúdicas foram realizadas na Unidade de Internação Pediátrica do Hospital Universitário/UFSC e atingiram crianças de zero a quatorze anos e seus acompanhantes, provenientes de diversas regiões de Santa Catarina. As atividades aqui descritas referemse àquelas desenvolvidas no período de fevereiro a dezembro de 2006.

Levantamento interno da instituição ${ }^{14}$ identifica que o perfil da população atendida é de pessoas provenientes de famílias de 
baixa renda, com poucos recursos de saneamento básico, com baixo grau de escolaridade ( $1^{\circ}$ grau incompleto), renda mensal média de 1,5 salário mínimo, com ocupações profissionais que demandam pouca qualificação técnica (construção civil, serviços gerais, faxina, autônomos...). Com relação às doenças atendidas, as mais comuns são referentes a problemas respiratórios, associados a outros como desnutrição, escabiose, síndrome diarréico.

As atividades foram desenvolvidas por alunos de graduação, de $4^{\mathrm{a}}$ e $5^{\mathrm{a}}$ fases, do curso de Psicologia, que no decorrer do texto serão denominados de Brinquedistas, que eram os monitores responsáveis pela realização das atividades lúdicas.

Em média, houve o envolvimento de 07 crianças e acompanhantes de forma direta/dia, com atenção continuada durante as brincadeiras. Além destas, diariamente, outras crianças e acompanhantes receberam algum tipo de atenção eventual ou apenas empréstimo de material para desenvolver as atividades.

As brincadeiras adequavam-se às possibilidades do paciente, sendo que estas eram realizadas na sala destinada à Brinquedoteca, dentro da Unidade de Internação Pediátrica, no próprio leito, quando os pacientes estavam impossibilitados de se deslocarem, e até mesmo em áreas externas ao hospital, como o lago e o parquinho existentes nas imediações do hospital.

\section{Materiais}

Os materiais utilizados foram: jogos diversos, peças de encaixe com vários níveis de complexidade, bonecas, fantoches, brinquedos de casinha, carrinhos, chocalhos, móbiles, quebra-cabeças, jogos de memória, dominós, materiais de pintura, massas de modelar, livros de colorir e com atividades educativas, livros de história, gibis, aparelho de som e materiais de papelaria variados (lápis, caneta hidrocor, tesoura, cola, papéis e outros).

\section{Procedimento}

O projeto desenvolveu-se em duas fases, sendo que a primeira foi de familiarização dos brinquedistas com a instituição e posteriormente o desenvolvimento das atividades com as crianças hospitalizadas e seus acompanhantes.

No primeiro momento, foram realizadas observações da unidade de internação, identificação da rotina hospitalar a que as crianças estavam submetidas, delineamento do perfil da clientela, levantamento de suas necessidades e interesses lúdicos, levantamento bibliográfico e leituras pertinentes ao tema de trabalho, planejamento das atividades e apresentação do projeto para a equipe de saúde, bem como, a organização dos brinquedos para as devidas atividades.

Após essa etapa, os brinquedistas passaram a realizar atividades lúdicas de segunda à sexta-feira, durante 4 horas diárias. A rotina se baseava em, primeiramente, ir à enfermaria para verificar os prontuários das crianças internadas, obtendo-se assim informações sobre sua saúde, suas idades, o sexo e informações que poderiam ser relevantes no momento da brincadeira. A seguir, era oferecido o serviço de recreação hospitalar às crianças e identificava-se a disponibilidade e motivação destas para a atividade. Com estas informações e, considerando o período de desenvolvimento, buscavam-se, dentre os brinquedos disponíveis os mais adequados.

No momento da conclusão das atividades diárias, as crianças tinham a opção de permanecerem com os brinquedos, garantindo que pudessem brincar por mais tempo, não ficando as brincadeiras limitadas apenas à presença dos brinquedistas.

Todos os materiais utilizados sempre eram higienizados diariamente, respeitando as normas e orientações da instituição hospitalar, e todas as atividades desenvolvidas recebiam a supervisão dos profissionais envolvidos (professor e psicólogo da instituição), semanalmente. No primeiro momento, foram realizadas 
observações da unidade de internação, identificação da rotina hospitalar a que as crianças estavam submetidas, delineamento do perfil da clientela, levantamento de suas necessidades e interesses lúdicos, levantamento bibliográfico e leituras pertinentes ao tema de trabalho, planejamento das atividades e apresentação do projeto para a equipe de saúde, bem como, a organização dos brinquedos para as devidas atividades.

\section{RESULTADOS E DISCUSSÃO}

No momento de propor atividades para as crianças, buscou-se facilitar a interação entre acompanhante-criança com o objetivo de otimizar sua relação. Procurou-se também, incentivar as interações entre as crianças hospitalizadas com a finalidade de promover um ambiente de descontração. Se havia crianças de idades próximas, era proposta alguma atividade dirigida, em grupo, como jogar dominó, pintar ou brincar de casinha. As brincadeiras realizadas mais freqüentemente foram: quebracabeça, memória, brinquedos de casinha e pintura. No primeiro momento, foram realizadas observações da unidade de internação, identificação da rotina hospitalar a que as crianças estavam submetidas, delineamento do perfil da clientela, levantamento de suas necessidades e interesses lúdicos, levantamento bibliográfico e leituras pertinentes ao tema de trabalho, planejamento das atividades e apresentação do projeto para a equipe de saúde, bem como, a organização dos brinquedos para as devidas atividades.

Pôde-se observar que as crianças, de fato, passaram a lidar melhor com a hospitalização através das atividades lúdicas realizadas com elas. Muitas vezes, as crianças estavam muito apáticas ou extremamente agitadas e, depois de brincarem, ficavam mais calmas e relaxadas, verbalizando seu contentamento e desejo de continuar brincando. A família e a equipe valorizavam a brincadeira e utilizavam este recurso para se aproximar da criança e formar vínculo.

Os resultados foram ao encontro da literatura estudada, ${ }^{1,3,10,13,15}$ confirmando que o brincar favorece o desenvolvimento durante o período de adoecimento e hospitalização, bem como é uma forma da criança expressar seus sentimentos, minimizando o seu sofrimento. Verificou-se também o brincar como uma forma de enfrentamento da hospitalização, tanto para as crianças como para os seus pais, como sugerem Motta e Enumo. ${ }^{10}$

As atividades em grupo proporcionaram um ambiente de descontração e de colaboração. As crianças foram estimuladas a realizarem atividades juntas, aproximando aquelas que permaneciam nos leitos daquelas que podiam sair. Os brinquedistas propunham brincadeiras capazes de agrupar todas as crianças, de acordo as suas possibilidades. Nestas situações, as regras da brincadeira eram estabelecidas em acordo grupal, o que fazia as crianças colocarem suas opiniões e idéias. Notou-se que estas atividades favoreciam a autonomia e a tomada de decisão, proporcionando um controle sobre situações vivenciadas no hospital. Assim, as crianças passaram a ter a possibilidade de tomar algumas decisões, 0 que não acontece freqüentemente durante a hospitalização.

As atividades lúdicas, ao propiciarem situações de tomadas de decisão e autonomia, transformaram o ambiente hospitalar despersonalizante em um lugar mais previsível e controlável para a criança. Estes comportamentos favoreceram o enfrentamento das dificuldades oriundas da hospitalização e também aproximaram o ambiente do hospital da realidade cotidiana das crianças. Assim, possibilitaram um maior bem estar da criança reafirmando os achados de Motta e Enumo. ${ }^{12}$

Os acompanhantes, visitantes e a equipe de saúde eram convidados a participar da proposta lúdica, o que favorecia um ambiente 
descontraído. Estas atividades conjuntas promoviam um relacionamento agradável entre os profissionais, os familiares e as crianças. A melhora nas relações sociais observadas reafirma as colocações de Novaes ${ }^{13}$ sobre a possibilidade do brincar no contexto hospitalar ser um instrumento de humanização, auxiliando nas inter-relações entre os profissionais e a criança, e entre estes e a família, bem como entre as próprias crianças hospitalizadas.

As brincadeiras na área externa do hospital, onde há um lago, gramado, bancos e brinquedos como balanço, casinha e gangorra, foram importantes para a criança dar continuidade ao seu desenvolvimento motor. O uso de espaços pertencentes ao hospital e à própria unidade de internação para realização de atividades lúdicas contribuiu para a compreensão deste local como um contexto de desenvolvimento para as crianças e suas famílias, como sugere Bronfenbrenner. ${ }^{2}$

A forma como este contexto é utilizado pelos profissionais pode potencializar as capacidades das famílias e suas crianças de se desenvolverem mesmo em condições de crise, como a hospitalização. O brincar se mostrou como um instrumento eficaz na manutenção e promoção de desenvolvimento infantil, conforme afirmado na literatura $1,3,10,13,15$

As atividades de supervisão favoreceram a aprendizagem teórica e possibilitaram a construção de relações entre a teoria estudada e as práticas realizadas. Estas atividades proporcionaram subsídios para o desenvolvimento do projeto de forma efetiva e coerente com a realidade encontrada, bem como, foi o momento de expor as dúvidas, dificuldades e ansiedades dos brinquedistas, avaliar o andamento do projeto e propor mudanças e adaptações quando necessário.
O projeto de extensão concretiza as necessidades atuais dos hospitais e possibilita os recursos financeiros para obtenção de materiais e recursos humanos fundamentais para que o projeto ocorra. Considera-se que o intercâmbio da Universidade com a comunidade seja imprescindível na formação dos alunos e no trabalho docente.

As atividades desenvolvidas pelos alunos de graduação em Psicologia propiciaram sua melhor compreensão sobre a atuação do psicólogo no ambiente hospitalar, ampliando conceitos e práticas de promoção de saúde no espaço da hospitalização infantil. Esta vivência enriqueceu a formação dos alunos, pois ampliou o entendimento sobre as possibilidades de intervenção do psicólogo, bem como o conhecimento acerca das políticas públicas de saúde, especialmente àquelas relacionadas à política de humanização no atendimento.

Iniciativas como esta devem ser ampliadas, tanto com projetos de extensão como de pesquisas. Esta área possui uma amplitude de especificidades a serem estudadas visando o melhor atendimento das crianças e suas famílias, bem como formação técnica das equipes. Sugerem-se novos projetos com a participação de diferentes profissionais da área da saúde, como enfermagem, serviço social, terapia ocupacional, medicina, nutrição, entre outros. A possibilidade de atuação multidisciplinar pode potencializar as consequências positivas da brincadeira no contexto hospitalar, proporcionando saúde e educação em saúde para as crianças e suas famílias, além do desenvolvimento de novas tecnologias adequadas para o trabalho com esta população, nas várias áreas de conhecimento. 


\section{REFERÊNCIAS}

1. Blanco, MPP. El Niño Hospitalizado: Caracteristicas, evaluación y tratamiento. Madrid: Pirámide; 1999.

2. Bronfenbrenner, U. Ecology of the family as a context for human development: reserch perspectives. Developmental Psycology. 1986; 22(6): 723-742.

3. Ceccim, RB, Carvalho, PRA. Criança hospitalizada: A atenção integral como uma escuta à vida. Porto Alegre: Ed. UFRGS; 1997.

4. Chiattone, HBC. A criança e a hospitalização. In: Angerami-Camon VA, Chiattone HBC, Meleti MR, organizadores. A Psicologia no hospital. São Paulo: Pioneira Thomson Learning; 2003. p. 23-100.

5. Crepaldi, MA, Rabuske, MM, Gabarra, LM. Modalidades de atuação do psicólogo em psicologia pediátrica. In: Crepaldi MA, Perosa GB, Linhares MB, organizadores. Temas em Psicologia Pediátrica. São Paulo: Casa do Psicólogo; 2006. p. 13-55.

6. Crepaldi, MA. Hospitalização na infância: Representações sociais da família sobre a doença e a hospitalização de seus filhos. Taubaté/SP: Cabral Ed. Universitária; 1999.

7. Junqueira, MFPS. A mãe, seu filho hospitalizado e o brincar: um relato de experiência. Estudos de Psicologia. 2003; 8(1): 163-197.

8. LEI no. 11.104 de 21 de março de 2005. Disponível em: https:// www.planalto.gov.br/ccivil_03/_Ato20042006/2005/Lei/L11104.htm.. Acesso em: 29/ago/06.

9. Linhares, MB. Psicologia Pediátrica: aspectos históricos e conceituais. In: Anais do VII Ciclo em Saúde Mental. Ribeirão Preto, 2000.

10. Mello, CO, Goulart, CMT, Ew, RA, Moreira, AM, Sperb TM. Brincar no Hospital: Assunto para Discutir e Praticar. Psicologia: Teoria e Pesquisa. 1999; 1: 6574.

11. Melo, LL, Valle, ERM. Brincando no Hospital: possibilidade ou realidade? Pediatria Moderna. 2002; 7: 328- 330.

12. Motta, AB, Enumo, SRF. Brincar no hospital: estratégia de enfrentamento da hospitalização infantil. Psicologia em Estudo. 2004; 9(1): 19-28.

13. Novaes, LHS. Brincar é Saúde: o alívio do estresse na criança hospitalizada. Pelotas: EDUCAT; 1998.

14. Relatório de Identificação da Demanda de Atendimento do Serviço Social da Pediatria do HU/UFSC, do ano de 2005.

15. Sampaio, EA, Novaes, LHVS. Brincar é também aprender? Pediatria moderna. 2001; 37(4): 38-144.

Recebido em: 12 de fevereiro de 2009.

Modificado em: 29 de abril de 2009. Aceito em: 30 de junho de 2009. 